\title{
Synthesis and Corrosion Inhibition Study of Benzothiazepine Derivatives on Mild Steel In Acid Medium
}

\author{
T. SASIKALA ${ }^{1}$, K.PARAMESWARI ${ }^{2}$ and S.CHITRA ${ }^{2}$ \\ 'Department of Biotechnology, Hindusthan College of Arts and Science, Coimbatore-28. India. \\ ${ }^{2}$ Department of Chemistry, P.S.G.R. Krishnammal College for Women, Coimbatore-04. India. \\ ${ }^{*}$ Correspondign authour E-mail: sasikanagu@yahoo.co.in
}

http://dx.doi.org/10.13005/ojc/320248

(Received: January 05, 2016; Accepted: February 09, 2016)

\begin{abstract}
2-ethoxy-4-(4-phenyl-2, 3-dihydro-1, 5-benzothiazepin-2-yl) phenol (EPBTZ) and 2-(4methoxyphenyl)-4-phenyl-2, 3-dihydro-1, 5-benzothiazepine (MPPBTZ) were synthesized by the condensation reaction between o-aminothiophenol and chalcone. The synthesized benzothiazepines were characterized by FTIR spectra. Their corrosion inhibition property on mild steel in sulphuric acid medium was investigated by weight loss and electrochemical techniques. Scanning electron microscopic studies were employed to examine the surface morphology of the inhibited and uninhibited metal samples. The compound EPBTZ revealed good corrosion protection property than MPPBTZ at all the temperatures studied. Electrochemical studies showed that the inhibitors behave as mixed type inhibitor retarding both cathodic and anodic corrosion reaction by forming an adsorbed protective layer.
\end{abstract}

Keywords: Mild steel, benzothiazepine, corrosion inhibitors, impedance, polarization.

\section{INTRODUCTION}

Corrosion of metals poses serious economic challenge to industries. Mild steel finds prominent application as structural material which is prone to corrosion in acidic medium. This problem paid the interest to corrosion scientists and engineers globally, to understand the mechanism and phenomenon of corrosion and to find appropriate solution to inhibit corrosion. Use of organic compounds containing heteroatoms and aromatic rings is one of the practical methods to inhibit corrosion ${ }^{1}$.
Benzothiazepine received the attention of many researchers due to its wide pharmacological and biological applications over the past two decades $^{2}$ but the use of benzothiazepine as corrosion inhibitors has not been reported. The aim of the present investigation is to synthesize two benzothiazepine derivatives and to study the inhibition efficiency for the corrosion of mild steel in $1 \mathrm{M} \mathrm{H}_{2} \mathrm{SO}_{4}$ using weight loss, electrochemical techniques and quantum chemical calculations. 


\section{MATERIALS AND METHODS}

\section{Synthesis of benzothiazepine}

The 1, 5-benzothiazepine were synthesized by the condensation reaction between o-aminothiophenol and chalkone ${ }^{3}$
The synthesized inhibitor was characterized by FTIR spectra.

\section{S.No IUPAC Nomenclature Structure}

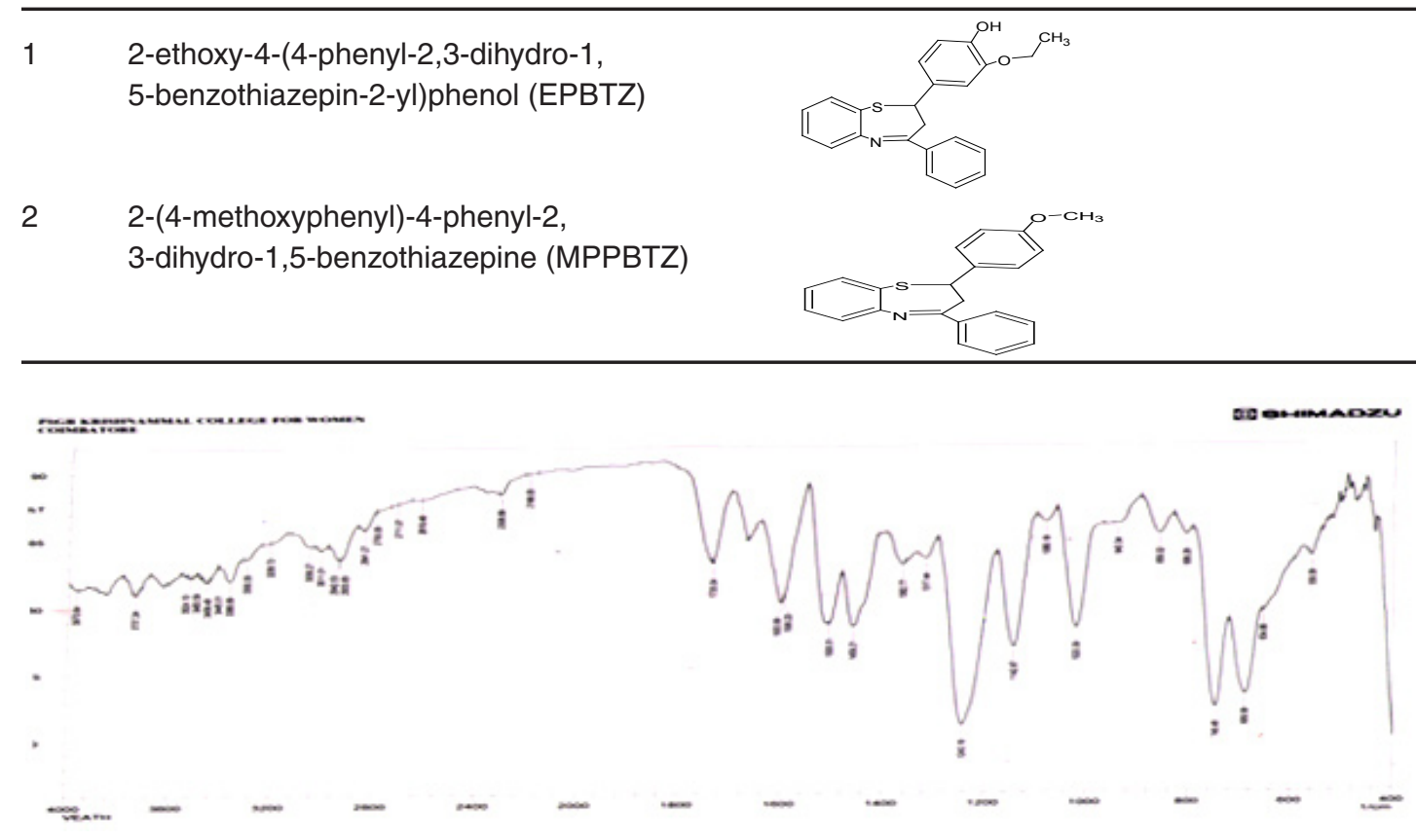

Fig.1: FTIR Spectrum of EPBTZ

FTIR spectra: ${ }^{\circ} \mathrm{C}=\mathrm{N}-1600 \mathrm{~cm}^{-1},{ }^{v} \mathrm{C}-\mathrm{S}-654 \mathrm{~cm}^{-1}, \mathrm{C}-\mathrm{N}-1243 \mathrm{~cm}^{-1}$

\section{Material preparation}

Mild steel specimens of dimensions $1 \mathrm{~cm}$ $X 3 \mathrm{~cm} \times 0.1 \mathrm{~cm}$ with composition of $0.084 \% \mathrm{C}$, $0.369 \% \mathrm{Mn}, 0.129 \% \mathrm{Si}, 0.025 \% \mathrm{~S}, 0.022 \% \mathrm{Cr}$, $0.01 \% \mathrm{Mo}, 0.015 \% \mathrm{Ni}$ and remaining iron were used for weight loss measurements. For electrochemical measurements, mild steel rod of same composition embedded in Teflon with exposed area of $0.785 \mathrm{~cm}^{2}$ was used. The specimens were polished with various grades of emery sheets, washed with double distilled water, degreased with acetone and dried. The specimens were stored in a desicator.

\section{Weight loss measurements}

The corrosion media used is $1 \mathrm{M} \mathrm{H}_{2} \mathrm{SO}_{4}$ $(100 \mathrm{ml})$ without and with addition of the inhibitor. The pre weighed mild steel specimens in triplicate were immersed in the medium for 3 hours. The mild steel specimens were then removed, washed with double distilled water, dried and reweighed. From the initial and final weights of the specimen, the average weight

\section{LANGMUIR PLOT}

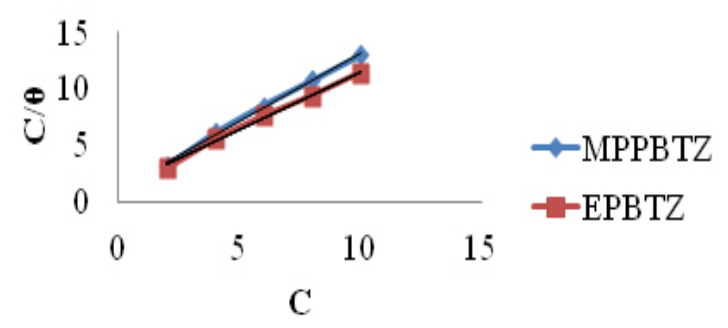

Fig. 2: Langmuir adsorption isotherm plots of benzothiazepine 
loss of the triplicates was recorded. The inhibition efficiency, corrosion rate and surface coverage were calculated from the weight loss using the formula,

Efficiency of Inhibitor $=[($ Weight Loss without inhibitor- Weight loss with inhibitor)/Weight loss without inhibitor] X100

Corrosion rate $(\mathrm{mpy})=[(534 \mathrm{X}$ Weight loss in mgms $)$ / (Density X Area in sq. inch X Time in hours)]

Surface coverage $(\theta)=[$ (Weight loss without inhibitor - Weight loss with inhibitor)/ Weight loss without inhibitor]

Where, $\theta$ is the surface coverage. The above procedure was repeated at different temperatures (313-333K).

\section{Electrochemical techniques}

Electrochemical measurements were carried out with three electrode cell assembly using IVIUM compact stat with IVIUM SOFT software. The mild steel rod was used as working electrode, a platinum wire and a standard calomel electrode were used as auxiliary and reference electrodes respectively. The electrochemical impedance spectroscopic measurements were obtained in the frequency range of $10 \mathrm{KHz}$ to $0.01 \mathrm{KHz}$ at the open circuit potential with peak to peak amplitude of $10 \mathrm{mV}$. From the Nyquist plot the charge transfer resistance $\left(R_{c t}\right)$ and double layer capacitance $\left(C_{d l}\right)$ were calculated.

$$
\text { I.E }(\%)=\left[\left(\mathrm{R}_{\mathrm{ct}}{ }^{*}-\mathrm{R}_{\mathrm{ct}}\right) / \mathrm{R}_{\mathrm{ct}}{ }^{*}\right] \times 100
$$

Where, $\mathrm{R}_{\mathrm{ct}}$ and $\mathrm{R}_{\mathrm{ct}}{ }^{*}$ are the charge transfer resistance obtained in the absence and presence of the inhibitors.

The potentiodynamic polarization curves were obtained at a sweep rate of $1 \mathrm{mV} / \mathrm{s}$ starting from$200 \mathrm{mV}$ to $+200 \mathrm{mV}$ at the open circuit potential.

$$
\operatorname{I.E}(\%)=\left[\left(I_{\text {corr }}-I_{\text {corr(inh })}\right) / I_{\text {corr }}\right] \times 100
$$

Table 1: Inhibition efficiency of various concentrations of the inhibitors for corrosion of mild steel in $1 \mathrm{M} \mathrm{H}_{2} \mathrm{SO}_{4}$ obtained by weight loss measurements at room temperature

\begin{tabular}{lccccc}
\hline Inhibitor & $\begin{array}{c}\text { Concentration } \\
(\mathbf{p p m})\end{array}$ & $\begin{array}{c}\text { Weight loss } \\
\mathbf{( g )}\end{array}$ & $\begin{array}{c}\text { Inhibition } \\
\text { Efficiency } \\
\mathbf{( \% )}\end{array}$ & $\begin{array}{c}\text { Degree of } \\
\text { surface } \\
\text { coverage( } \theta)\end{array}$ & $\begin{array}{c}\text { Corrosion rate } \\
(\mathbf{m p y})\end{array}$ \\
\hline BLANK & - & 0.2656 & - & - & 17466.71 \\
EPBTZ & 2 & 0.087 & 67.24 & 0.6724 & 5721.40 \\
& 4 & 0.0746 & 71.91 & 0.7191 & 4905.93 \\
& 6 & 0.0618 & 76.73 & 0.7673 & 4064.16 \\
& 8 & 0.0405 & 84.75 & 0.8475 & 2663.41 \\
& 10 & 0.0351 & 86.78 & 0.8678 & 2308.28 \\
MPPBTZ & 2 & 0.0986 & 62.87 & 0.6287 & 6484.25 \\
& 4 & 0.0920 & 65.36 & 0.6536 & 6050.21 \\
& 6 & 0.0770 & 71.00 & 0.7100 & 5063.76 \\
& 8 & 0.0700 & 73.64 & 0.7364 & 4603.42 \\
& 10 & 0.0650 & 77.22 & 0.7722 & 3978.67 \\
\hline
\end{tabular}

Table 2: Adsorption parameters calculated from the Langmuir adsorption isotherm

\begin{tabular}{lcccccc}
\hline Compound & Temperture (K) & Kads & $\mathbf{R}^{2}$ & $-\Delta \mathbf{G}$ & slope & Intercept \\
\hline EPBTZ & 303 & 1.005 & 0.999 & 10.13 & 1.04 & 1.13 \\
MPPBTZ & 303 & 0.884 & 0.998 & 9.80 & 1.22 & 0.99 \\
\hline
\end{tabular}




\section{SEM Study}

The surfaces of the mild steel plates after immersion in blank acid and acid containing maximum concentration of the inhibitors were examined using Medzer Biomedical research microscope (Shimadzu, Japan).

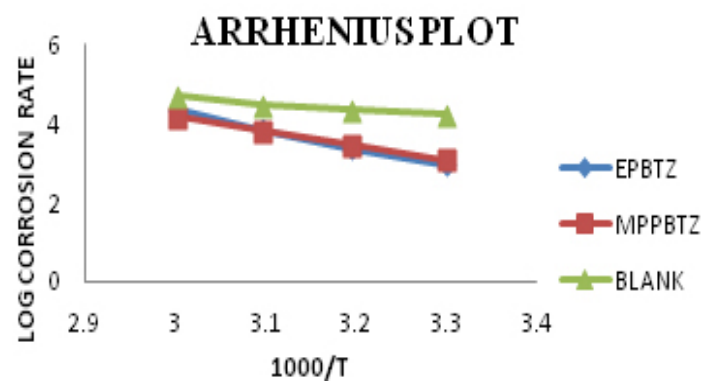

Fig. 3: Arrhenius plots of corrosion of mild steel in $1 \mathrm{M} \mathrm{H}_{2} \mathrm{SO}_{4}$ solution in the absence and presence of inhibitor

\section{RESULTS AND DISCUSSION}

\section{Weight loss measurements}

The corrosion rate of mild steel with the addition of the benzothiazepines in $1 \mathrm{M} \mathrm{H}_{2} \mathrm{SO}_{4}$, inhibition efficiency and surface coverage $(\theta)$ are presented in Table1. From the table it is clear that there is an increase in inhibition efficiency with increase in concentration. At $10 \mathrm{ppm}$ the efficiency reached an optimum value. Beyond this concentration, the efficiency was found to be almost constant.

\section{Adsorption isotherm}

The interaction between the inhibitor and mild steel surface can be studied using adsorption isotherms. The surface coverage values $(\theta)$ obtained from weight loss method and were tested by fitting to various isotherms. It was found that the best fit was

Table 3: Inhibition efficiencies of the inhibitor for corrosion of mild steel in $1 \mathrm{M} \mathrm{H}_{2} \mathrm{SO}_{4}$ obtained by weight loss measurements at higher temperatures

\begin{tabular}{lcccc}
\hline $\begin{array}{l}\text { Name of the } \\
\text { inhibitor }\end{array}$ & $\begin{array}{c}\text { Temperature } \\
(\mathbf{K})\end{array}$ & $\begin{array}{c}\text { Weight loss } \\
\mathbf{( g )}\end{array}$ & $\begin{array}{c}\text { Inhibition } \\
\text { efficiency (\%) }\end{array}$ & $\begin{array}{c}\text { Corrosion } \\
\text { rate(mpy) }\end{array}$ \\
\hline Blank & 303 & 0.0885 & - & 17460.14 \\
& 313 & 0.1152 & - & 22727.60 \\
& 323 & 0.1443 & - & 28468.69 \\
EPBTZ & 333 & 0.2486 & - & 49045.85 \\
& 303 & 0.0117 & 86.77 & 2308.27 \\
& 313 & 0.0206 & 76.77 & 4064.13 \\
MPPBTZ & 323 & 0.0298 & 68.58 & 5484.61 \\
& 333 & 0.0324 & 63.38 & 6392.13 \\
& 303 & 0.0201 & 77.28 & 3965.49 \\
& 313 & 0.0233 & 73.67 & 4596.81 \\
& 323 & 0.0298 & 66.32 & 5879.18 \\
& 333 & 0.0348 & 60.67 & 6865.63 \\
\hline
\end{tabular}

Table 4: Kinetics/Thermodynamic Parameters of mild steel corrosion in $1 \mathrm{M} \mathrm{H}_{2} \mathrm{SO}_{4}$

\begin{tabular}{lccccccc}
\hline $\begin{array}{l}\text { Name of the } \\
\text { inhibitor }\end{array}$ & $\mathbf{E}_{\mathbf{a}}(\mathbf{k J})$ & $\mathbf{3 0 3 K}$ & $\begin{array}{c}\Delta \mathbf{G}^{0}{ }_{\text {ads }} \\
\mathbf{3 1 3 K}\end{array}$ & $\mathbf{3 2 3 K}$ & $\mathbf{3 3 3 K}$ & $\begin{array}{c}-\Delta \mathbf{H}^{\mathbf{0}} \\
\mathbf{k J} / \mathbf{m o l e}\end{array}$ & $\begin{array}{c}-\Delta \mathbf{S}^{0} \\
\mathbf{k J} / \mathbf{m o l e}\end{array}$ \\
\hline BLANK & 27.7 & - & - & - & - & 12.18 & 0.64 \\
EPBAZ & 37.59 & -9.05 & -7.56 & -6.69 & -6.26 & 34.7 & 0.60 \\
MPPBTZ & 31.06 & -7.40 & -7.13 & -6.42 & -5.94 & 42.4 & 0.89 \\
\hline
\end{tabular}


obtained with Langmuir isotherm which is expressed as

$$
C / \theta=1 / K_{\text {ads }}+C
$$

Where $\mathrm{C}$ is the concentration of the inhibitor and $\mathrm{K}_{\mathrm{ads}}$ is the adsorption equilibrium constant for the adsorption desorption process. $\mathrm{K}_{\text {ads }}$ represents the adsorption power of the inhibitor molecule on the surface. The linear plots $(\mathrm{C} / \theta \mathrm{Vs} \mathrm{C})$ obtained in Figure 2 with correlation coefficient $R^{2}=0.99$ suggest that the adsorption of the studied inhibitors from $1 \mathrm{M}$ $\mathrm{H}_{2} \mathrm{SO}_{4}$ followed Langmuir adsorption isotherm. The intercept of the plot on the $y$-axis gives the value of $1 / \mathrm{K}$ from which $\mathrm{K}$ can be obtained. The positive value confirms the adsorbability of the inhibitors on the metal surface. Kads is related to $\Delta \mathrm{G}_{\text {ads }}$ as,

$$
\Delta G_{\text {ads }}=-R T \ln \left(55.5 K_{\text {ads }}\right)
$$

The value 55.5 is molar concentration of water. The value of " $\mathrm{G}_{\mathrm{ads}}$ is found to be negative and less than - $40 \mathrm{KJ} / \mathrm{mole}$ (Table: 3 ) suggesting that the adsorption of the studied benzothiazepines are spontaneous and involves electrostatic interaction with the mild steel surface.

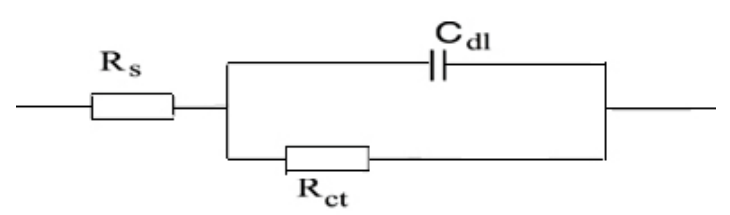

Fig. 4: Equivalent circuit model used for simulation of data
The slope, equilibrium constant and regression coefficient are given in Table 2.

\section{Effect of temperature}

The effect of temperature on corrosion and inhibition efficiency of the inhibitors was studied by conducting weight loss measurements at 303-333K. The data are given in Table3.

As the temperature increases, the inhibition efficiency was found to decrease. This may be due to increased rate of desorption of the inhibitor molecules at higher temperatures. The activation energy $\left(E_{a}\right)$ calculated from the slopes of the Arrhenius plot (Figure 3) of the inhibited solutions was higher than the blank acid solution suggesting strong adsorption of the molecule on steel surface ${ }^{4}$. This increases the activation energy for corrosion process. The values of thermodynamic parameters such as enthalpy and entropy of activation were calculated from the slopes and intercepts of the transition state plot (log

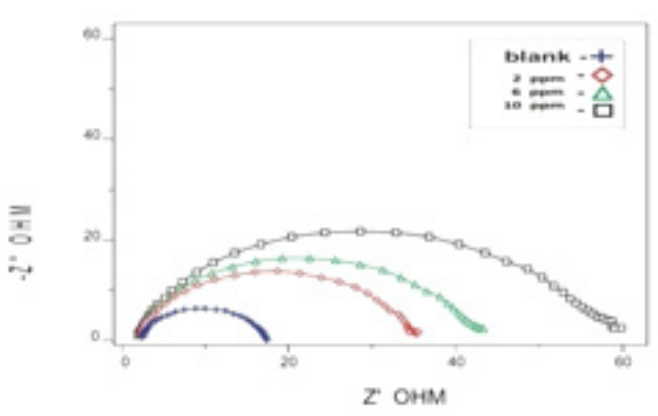

Fig. 5: Nyquist diagram for mild steel in $1 \mathrm{M}$ $\mathrm{H}_{2} \mathrm{SO}_{4}$ for selected concentrations of inhibitor (EPBTZ)

Table 5: AC-impedance parameters for corrosion of mild steel for

\begin{tabular}{|c|c|c|c|c|}
\hline $\begin{array}{l}\text { Name of } \\
\text { the inhibitor }\end{array}$ & $\begin{array}{c}\text { Concentration } \\
\text { (ppm) }\end{array}$ & $\begin{array}{c}\text { Rct } \\
(\text { ohm cm²) }\end{array}$ & $\begin{array}{c}\text { Cdl } \\
\left(\mu \mathrm{F} / \mathrm{cm}^{2}\right)\end{array}$ & $\begin{array}{c}\text { Inhibition } \\
\text { efficiency (\%) }\end{array}$ \\
\hline BLANK & - & 11.06 & 27.8 & - \\
\hline \multirow[t]{3}{*}{ EPBTZ } & 2 & 34.0 & 22.6 & 67.47 \\
\hline & 6 & 48.2 & 23.8 & 77.05 \\
\hline & 10 & 84.2 & 21.2 & 86.86 \\
\hline \multirow[t]{3}{*}{ MPPBTZ } & 2 & 30.2 & 26.3 & 63.33 \\
\hline & 6 & 38.4 & 27.4 & 71.19 \\
\hline & 10 & 47.3 & 26.7 & 76.61 \\
\hline
\end{tabular}
selected concentrations of the inhibitor in $1 \mathrm{M} \mathrm{H}_{2} \mathrm{SO}_{4}$ 
corrosion rate/T Vs $1 / T$ ). The slope of the straight line is equal to $\Delta \mathrm{H}_{\text {ads }} / 2.303 \mathrm{R}$ and intercept equal to $\log \mathrm{R} / \mathrm{Nh}+\Delta \mathrm{S}_{\mathrm{ads}} / 2.303 \mathrm{R}$. The values are recorded in Table 4.

The negative values of "H suggest that the adsorption of the benzothiazepines on mild steel is an exothermic process ${ }^{5}$. The $\Delta \mathrm{G}_{\mathrm{ads}}$ values are less than $-20 \mathrm{KJ} / \mathrm{mol}$ which implies physisorption of benzothiazepine on the mild steel surface involving the positively charged surface and the lone pair of electrons on heteroatoms and $\pi$ electrons of the ring. "S values are negative suggesting that the adsorption of the inhibitor leads to an ordered state during adsorption.

\section{Electrochemical techniques}

Electrochemical impedance spectroscopy

The effect of EPBTZ on the impedance behavior of mild steel in $1 \mathrm{M} \mathrm{H}_{2} \mathrm{SO}_{4}$ is shown as Nyquist plots. The results are analyzed with an equivalent circuit model shown in Fig4. It is apparent from the plot that increase in the concentration of the inhibitor resulted in an increase in the impedance of the interface with increase in the diameter of the semicircles. $C_{d l}$ value decreased and the $R_{c t}$ value increased with increase in concentration. These results clearly indicate that the corrosion of mild steel in $1 \mathrm{M} \mathrm{H}_{2} \mathrm{SO}_{4}$ occurs through charge transfer process $^{6}$.

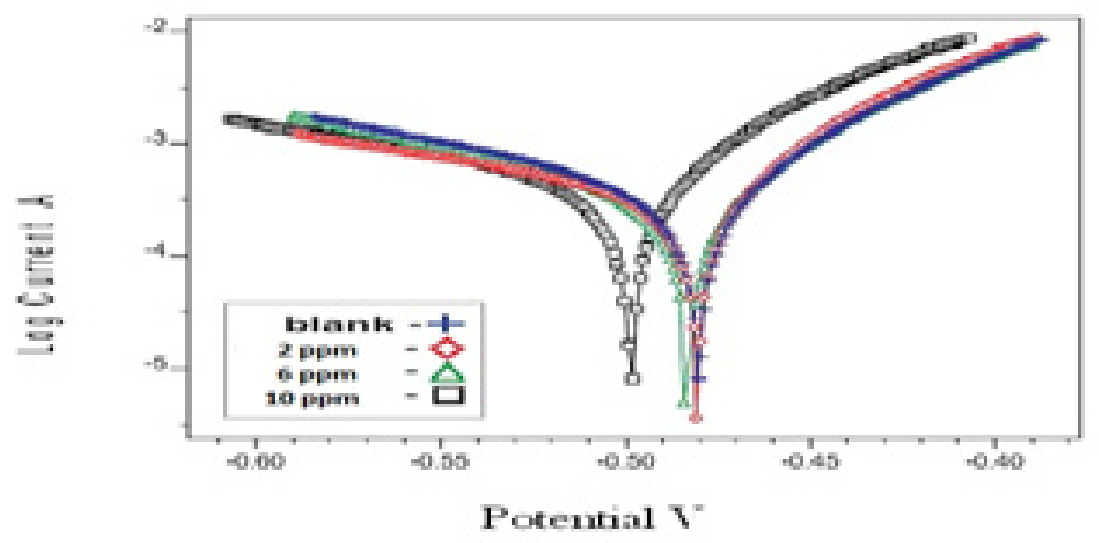

Fig. 6: Polarization curves for mild steel recorded in $1 \mathrm{M} \mathrm{H}_{2} \mathrm{SO}_{4}$ with selected concentrations of the inhibitor (EPBTZ)

Table 6: Corrosion parameters for corrosion of mild steel with selected concentrations of the inhibitors in $1 \mathrm{M} \mathrm{H}_{2} \mathrm{SO}_{4}$ by Potentiodynamic polarization method

\begin{tabular}{|c|c|c|c|c|c|c|}
\hline $\begin{array}{l}\text { Name of } \\
\text { the inhibitor } \\
\text { (\%) }\end{array}$ & $\begin{array}{l}\text { Concentration } \\
\text { (ppm) }\end{array}$ & $\begin{array}{l}\text { Tafel s } \\
\text { b a }\end{array}$ & $\begin{array}{c}\text { slopes(mV/dec) } \\
\text { bc }\end{array}$ & $\begin{array}{l}E_{\text {corr }} \\
(\mathrm{mV})\end{array}$ & $\begin{array}{c}\mathrm{I}_{\text {corr }} \\
\left(\mu \mathrm{Amp} / \mathrm{cm}^{2}\right)\end{array}$ & $\begin{array}{l}\text { Inhibition } \\
\text { efficiency }\end{array}$ \\
\hline BLANK & - & 61 & 137 & -491.0 & 414 & - \\
\hline \multirow[t]{3}{*}{ EPBTZ } & 2 & 57 & 154 & -463.2 & 140 & 66.18 \\
\hline & 6 & 62 & 160 & -454.3 & 101 & 75.60 \\
\hline & 10 & 65 & 167 & -452.3 & 52 & 87.43 \\
\hline \multirow[t]{3}{*}{ MPPBTZ } & 2 & 63 & 158 & -465.6 & 165 & 60.14 \\
\hline & 6 & 59 & 164 & -469.4 & 115 & 72.22 \\
\hline & 10 & 64 & 170 & -471.3 & 60 & 85.50 \\
\hline
\end{tabular}




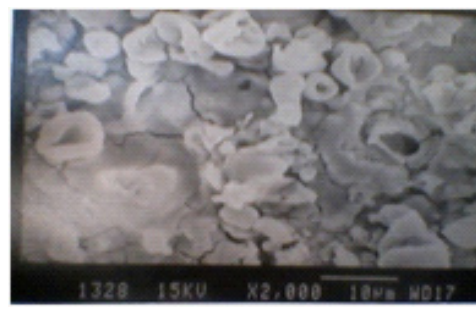

Fig. 7: SEM image of mild steel in the absence of inhibitor

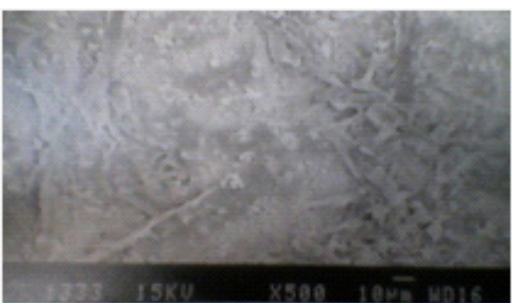

Fig. 8: SEM image of mild steel containing $10 \mathrm{ppm}$ of EPBAZ

Table 7: Optimized structure and Frontier molecular diagram

of the inhibitors EPBTZ and MPPBTZ

Structures

Table 8: Quantum Chemical parameters for the inhibitors

\begin{tabular}{lcccccc}
\hline Inhibitor & $\mathrm{E}_{\text {номо }}(\mathrm{eV})$ & $\mathrm{E}_{\text {Luмо }}(\mathrm{eV})$ & $\Delta \mathrm{E}(\mathrm{eV})$ & $\chi(\mathrm{eV})$ & $\eta(\mathrm{eV})$ & $\sigma(\mathrm{eV})$ \\
\hline EPBTZ & -5.38 & -1.61 & 3.77 & 3.49 & 1.88 & 0.53 \\
MPPBTZ & -5.61 & -1.55 & 4.05 & 3.58 & 2.03 & 0.49 \\
\hline
\end{tabular}

\section{Polarization study}

Polarization experiments were carried out to study the effect of the inhibitor on the electrochemical behavior of mild steel in $1 \mathrm{M} \mathrm{H}_{2} \mathrm{SO}_{4}$ without and with various concentration of the benzothiazepine. Electrochemical parameters such as corrosion potential $\left(\mathrm{E}_{\text {corr }}\right)$, corrosion current density $\left(\mathrm{I}_{\text {corr }}\right)$, cathodic and anodic Tafel slopes $\left(b_{c}\right.$ and $\left.b_{a}\right)$ were derived from tafel plots (Figure5). From the plots it is evident that addition of benzothiazepine decreased the cathodic current while in the anodic domain, the presence of inhibitor does not decrease the corrosion current. The inhibition efficiency was calculated using the equation,

$$
\text { I.E }(\%)=\left[\left(I_{\text {corr(Blank) }}-I_{\text {corr(inh) })}\right) / I_{\text {corr(Blank })}\right] \times 100
$$

From the results it is clear that $\mathrm{E}_{\text {corr }}$ values are shifted to less negative direction. Tafel slopes $b_{a}$ 
and $b_{c}$ are changed but $b_{c}$ is affected more. Hence the inhibitors can be regarded as mixed type but affect cathodic reaction more.

\section{SEM Study}

Fig 6 and 7 show the SEM micrographs of mild steel specimen immersed in blank acid and inhibited acid $\left(1 \mathrm{M} \mathrm{H}_{2} \mathrm{SO}_{4}+10 \mathrm{ppm}\right)$. It is clear that the surface of the mild steel in presence of the inhibitor is smoother when compared to the uninhibited solution, means that the corrosion of mild steel is reduced by the adsorbed layer of the inhibitor.

\section{Theoretical Calculations}

Quantum chemical calculations are used to correlate the molecular structure with the inhibition efficiency. Gaussian 03 program B3LYP/6-31G (d, p) was used and all calculations were carried out by complete geometry optimization. The optimized structure and frontier molecular orbital density distribution of the inhibitors are presented in Table7. The $\mathrm{E}_{\text {номо }}$ indicates the ability of the molecule to donate electrons whereas $\mathrm{E}_{\text {LUMO }}$ indicates the ability

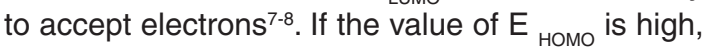
the molecule has a greater ability to donate electrons and greater will be the inhibition efficiency. The energy gap is an important parameter to study the adsorption of the inhibitor on the metallic surface. The inhibition efficiency of the molecule is increased with a decrease in the value of "E. A molecule with lower energy gap is termed as soft molecule as it is easily polarisable. The calculated quantum chemical parameters are tabulated (Table 8).

From the results shown, EPBTZ was found to be efficient inhibitor as it possess higher value of $E_{\text {номо }}(-5.38)$, lower value of $E_{\text {LuMO }}(-1.61)$ and higher value of ó (0.53). Generally it is believed that hard molecules have large energy gap whereas soft molecules have lower energy gap and are found to be more reactive ${ }^{9}$. From the above values, it is predicted that the inhibitor EPBTZ has lower energy gap $(3.77 \mathrm{eV})$. It can therefore be absorbed on to the surface of the mild steel more efficiently than MPPBTZ. This may be attributed to the additional anchoring -OH group in EPBTZ.

\section{CONCLUSION}

1. The synthesized benzothiazepine derivatives are good corrosion inhibitor for mild steel in sulphuric acid medium and act by adsorption

2. The adsorption of the compounds obey Langmuir adsorption isotherm.

3. Electrochemical study shows that they are mixed type but slightly cathodic.

4. SEM studies confirmed the formation of a protective film of the inhibitor on the mild steel surface.

\section{REFERENCES}

1. Babu R. R., Thangavel K., Anti corrosion methods and materials. 2005, 52, 219.

2. Khan A. J., Baseer M.A., Orient. J.Chem. 2011, 27, 1759.

3. Vutla V.R., Yejella R.P., Ramaraonadendla and Ramarao N. V., Der Pharmacia Letter, 2013, 5, 93.

4. Achary G., Sachin H. P., Arthoba Naik Y., Venkatesha T. V., Mater. Chem. Phys. 2008, 107, 44.
5. Gomma M. K., Wahdan M. H., Mater Chem. Phys. 1995, 39, 209.

6. Avci G., Colloids and Surfaces $A$ : Physicochem. Eng. Aspects. 2008, 317, 730.

7. Gece G., Corrosion Science. 2008, 50, 2981.

8. Zhang D. Q., Gao L. W., Zhou G. D., Corrosion science. 2004, 46, 3031.

9. Khaled K. F., Electrochimica Acta. 2010, 55, 6523. 